\title{
Leaving Orthodox Judaism
}

\author{
David Belfon
}

\section{1 \\ Introduction}

Leavetaking in Judaism is a deeply individual experience, very much informed by personal choices, power dynamics, as well as complex mechanics of identity change. My ongoing research study investigates the ways in which this process occurs in a Canadian context through interviews with twenty leavetakers from several varieties of Jewish observance in the Greater Toronto Area (GTA). Participants run the gamut of observant Judaism from the moderatelyobservant to highly-traditionalist former haredim (ultra-Orthodox). They range in age from early twenties to late forties, relating their experiences in an Orthodox community, the process of leaving, and their current lifestyle and self-identification. This chapter presents some preliminary findings of this work, wherein I have endeavored to give careful attention to the numerous identities that exist in-between and beyond the standard poles of observant Judaism-experiential categories that add a new dimension to studying leavetaking and disaffiliation.

There is no formal mechanism in place for leaving Judaism wholesale. According to longstanding Orthodox Jewish ethos (Babylonian Talmud, Sanhedrin 44a; Yevamot 47b), if a person is born Jewish or has undergone an authorised conversion into the tradition, they are considered Jewish in perpetuity. This standing remains immutable, regardless of their intent to leave the religion or if their community shuns them for divergent beliefs or activities. Renouncing religious beliefs does not correlate to leaving Judaism either, unlike in some Christian contexts (Roof and Hoge 1980), given that faith is not necessarily the core criterion for Jewish membership. Furthermore, there are no records of members "on the rolls" or officially "active," aside from synagogue affiliations (Lazerwitz and Harrison 1980). After all, "[m]embership in the Jewish faith is conferred by birth, not belief" (Phillips 2010: 81). Arguing for the centrality of "ethno-apostasy" in religious leaving and switching, Phillips and Kelner contend that "in Jewish culture the boundaries between religion and other aspects of life are blurred, and native discourse defines piety more in terms of practice rather than belief" (2006: 509). As such, one can identify with Judaism's cultural or ethnic dimensions aside from its spiritual and ritual elements (Troen 
2016), informally leave any Jewish denomination, community, or even selfidentify as a religious "none" (Pew Research Centre 2013)—while remaining technically Jewish.

As the most theologically-conservative and ritually-observant Jewish denominational stream, haredism has long been the subject of the majority of scholarly discussion on leavetaking in Judaism. Key issues including rituals, physical trappings, food and drink, gender relations, education, social interactions, and other matters of the everyday are governed by complex rules informed by religious authorities and the wider community within Orthodoxy. These entities enact and defend norms more fervently than other Jewish denominations that may be less intrinsically rigid and proscribed. The stakes, therefore, are arguably highest in leaving this highly-traditionalist environment. Socialisation is an especially powerful tool for cultivating Orthodox identities - especially among haredim - with schools training by instruction and modelling how to live a "Jewish" lifestyle. In this context, "Jewish" is a shorthand that treats strictly-Orthodox observance as normative Judaism and the vanguard for the only possibly legitimate practices and beliefs within the tradition, while emphasising chosenness both over non-Jews and less-observant Jews.

Leavetakers from these "Orthodoxies" conduct themselves in a manner contradicting the normative path of Torah observance and the religious lifestyle consistent with community standards. Experiences vary widely between and among the different denominational affiliations at issue, as well as concerning the various nuances of time and place that work to dictate different standards of orthodoxy and orthopraxy deemed as acceptable in a given community. Challenging community norms-especially concerning issues of orthopraxy and the legitimacy of community insularity - tend to be especially sensitive issues. Since community boundary maintenance against outside influences is considered imperative to continued Jewish endurance (Sarna 2004), a renunciation of community standards of comportment is of serious consequence to the entire community, and deviations can be quite public. When a religious change entails a shifting self-identification as a Jew, a complex series of events are set in motion that affect several crucial aspects of the leavetaker's ethnosocio-cultural lives in addition to their spiritual change or personal identification as part of the religious group. Because reputation and familial standing are so prevalent in maintaining an observant Jewish family's status within a community, a member's decreased observance may impact the immediate family and even the wider religious community in an intricate system of corollaries.

Given that secular concerns deemed non-essential tend to be kept at a distance from strictly-Orthodox experience owing to a concern that much secular 
culture is licentious or otherwise unpious, much of a leavetaker's experience in the city has been with Jewish institutions within a roughly-delineated enclave. The GTA being a region home to myriad religions and ethnicities can result in a leavetaker being thrust into an unfamiliar environment, with a limited practical and social toolkit with which to navigate their new experience. They may undertake this journey alone since leavetakers sometimes find themselves cut off from their families, friends and familiar strictly-Orthodox surroundingsthe only experience many have known up to that point. A discontented individual may not express their concerns for fear of community reprisal—even from close friends and family given the powerful taboos associated with lessened observance, and so may opt instead to live a double-life instead of openly leaving (Fader 2017). For some individuals on the conservative side of Orthodoxy and especially leavetakers from haredism, it can be an all-or-nothing decision to stay or leave their community.

Leavetaking from observant Judaism is not, however, always as conspicuous as typical notions of an insider-outsider dichotomy assumes it to be. Every participant in my ongoing study of leavetakers from Judaism in the GTA articulated experiencing a gradual process of doubting and secretly transgressing taboos. The various gradations of clandestine deviation or leavetaking oftentimes involve a deeply complex struggle as the individual "tests the waters" secretly while living a double-life of sorts before "coming out," weighing their inclination to leave often without an institutionalised support system to assist them. Normative observance is, therefore, a tall order given the high standards of personal piety that not everyone born into an observant family is willing or able to realise.

\section{Previous Research and Empirical Material}

Social scientific work on leavetaking from Judaism is a burgeoning field of study, but scholarship pertaining to this phenomenon in Canada is remarkably scarce, as are statistics of this invisible population. Only marginallyapproximate data exists, such as Starting a Conversation: A Pioneering Survey of Those Who Have Left the Orthodox Community (Trencher 2016), which offers general figures for mainstream Orthodox leavetakers in the United States.

The vast majority of available research on leavetaking in Judaism is demographic and informed by etic sensibilities, focusing particularly on denominational switching in Judaism (Sands et al. 2006; Hartman and Hartman 1999; Lazerwitz 1995). By virtue of these researchers' particular framework emphasising trends and quantitative analytics, these publications articulate hypotheses 
concerning experiential aspects that, in my view, merit qualitative scholarly consideration as well, especially since switching and decisive leavetaking are only roughly correlative to the experiences related by participants in my study.

Since Shaffir and Rockaway's 1987 work on haredi defection in Israel, several qualitative studies of Jewish leavetaking have emerged (Weiskopf 2016; Davidman 2014; Berger 2014; Topel 2012; Stadler 2009; Attia 2008; Davidman and Greil 2007; Winston 2005; Frankenthaler 2004; Herzbrun 1999) focusing on the diverse experiential aspects of this phenomenon. For example, Bar-Lev et al. (1997) addressed the culture-specific aspects of leavetaking from haredism in Israel, noting that the cultural, social, national, and ethnic dimensions of Judaism tend to persist in certain respects after leavetaking from the specifically religious and ritual dimensions, a finding that raises questions on how this might compare to leavetaking trajectories elsewhere. Other foci analyse data informed via Psychology (Weiskopf 2016) or address persons within a subculture different to the wider leavetaker community, as in Attia's (2008) work on adolescent ultra-Orthodox runaways.

An especially compelling manner of approaching leavetaking and disaffiliation has been considering how these phenomena parallel with increasing Jewish observance. Berger (2014) and Davidman and Greil (2007) have noted that studies dealing largely with "deconversion" from the Orthodoxy one joined and subsequently left are markedly different to the disaffiliation process in Judaism. Shaffir (1991) argues that in contrast to the socialisation process of becoming Orthodox - which for males occurs chiefly in and around the highly structured yeshiva (seminary) and synagogue experiences-a leavetaker's socialisation proceeds in the absence of any formalised supports or sympathetic and supportive subculture.

In my view, because there is no explicit conversion occurring in circumstances involving individuals who were born into an observant household, "deconversion" does not satisfactorily articulate their leavetaking trajectory, although some scholars of leavetaking in Judaism continue to favour "deconversion" nevertheless (Frankenthaler 2015, 2004). Rethinking "deconversion" compels researchers to study leavetaking as not simply an inversion of the oftstudied processes of religious conversion, but rather as its own distinct phenomenon. Davidman and Greil, following Beckford (1985), agree, adding that "[e]xit narratives also differ from conversion narratives in that exiters are less likely to be provided with readily available scripts with which they may tell their stories" (2007: 201). The distinct lack of formalised structural support or institutional guidance are products of the disaffiliation experience, as are a lack of readily available narrative types at their disposal — a very different experience to becoming Orthodox, where there are various supports and models 
at one's disposal. It is, therefore, crucial to analyse the fullness of a leavetaking account to isolate issues concerning scripting, modelling, and creativity as these people navigate the complexities of role and identity change from, within, back to, and out of Orthodoxies without the limiting implications that tend to be associated with "deconversion."

Even with their distinctive ranges of inquiry, researchers contributing to the burgeoning field of studying leavetakers in Judaism rarely make a meaningful distinction between the leavetaking experiences of strictly haredi interlocutors and observant-but-not-haredi leavetakers. Berger acknowledges this lacuna in her study of haredi leavetakers in New York, suggesting that "[f]uture research may help clarify the dynamics and correlates of diversity in the struggle with the issue of identity among 'exiters'" (2014: 93). My work embraces this largely neglected issue via its broader inclusion criteria than those typically advanced in scholarship on Jewish leavetaking. The study takes into account the wider milieu of observant Judaisms that engage in leavetaking which includes strictly ultra-Orthodox haredim in the GTA, as well as other religiously-conservative Jewish experiences. The resulting comparative data enables further insight into identity, trajectory and community alternatives at issue.

Concurrently to the nascent scholarly interest into leavetaking from Judaism, numerous memoirs from individual leavetakers from haredism have been published (Deen 2015; Deitsch 2015; Feldman 2014, 2012; Lax 2015; Vincent, 2014; Eichenstein 2013; Auslander 2007; Mann 2007). Although they lack scholarly rigor and are necessarily anecdotal, these accounts remain valuable cultural artifacts. They offer insight into the mechanics of leavetaking through a singular narrative, an essential window into post-hoc rationalisation and critical reflection of the leavetaking experience, expressed through the leavetaker's own words in an autobiographical sense while raising questions of how narrative varieties can facilitate or otherwise affect perceptions and audiences.

Several study interlocutors described becoming aware during our interview that they were only then working through their sense of identity vis-à-vis Judaism, developing their responses and rationalising their expressions in real time. False starts, slips of the tongue, code-switching, and vocalised idiosyncrasies are all significant data that lend insight into how a discussion on leavetaking can differ meaningfully from an edited, marketed, and published memoir. This analytical method is evocative of Stromberg's work on narratively constituted identity change in Evangelical conversion narratives (1993), where every utterance matters. For example, upon hearing about my familiarity with the GTA's varied Jewish landscape, participant "Ariel"1 described his previous observance

1 All interviewees have been anonymised and have been assigned pseudonyms. 
as being reflected through his institutional affiliations instead of claiming membership in any distinct Jewish denomination, noting only that he was "somewhere in the Orthodox camp" but that "lines were blurred." He did so by detailing at length which specific educational institutions and synagogues he attended in the past and describing the types of Judaism these institutions represent in the community's perception of Jewish piety in the city, utilising restricted code to articulate his former station without actually labeling it as a distinct denomination. At no point did Ariel spell this out to me-it became clear only when noticing that his expression omits traditional categories of denomination altogether. There is a palpable sense of the opacity of membership and observance here, largely governed by public opinion, personal resolve, and, in Ariel's individual arc, Jewish institutional affiliations.

\section{New Findings Focusing on "leaving religion"}

Because the "something else" leavetakers come to identify with in the marketplace of potential identities will likely be substantially different to the lifestyle they had been accustomed to previously, these identity changes are especially ripe for scholarly analysis. The more oblique, circuitous, and difficult to classify identifications within the largely overlooked reaches of Orthodoxy make evident the vacillations that exist between the poles of ultra-Orthodoxy, Modern Orthodoxy, and beyond.

This wider discourse on the permeability of boundaries in observant Judaism reveals variable conceptions of changing religiosity from - and, somewhat unpredictably, sometimes still within-observant Judaism, from decisive leavetaking to break-taking and eventual circling back, along the spectrum encountering the different ways in which a leavetaker re-evaluates their positioning in the tradition while presenting as a leavetaker nevertheless. A key question of this study pertains to the mechanisms through which leavetaking and disaffiliation can occur while the individual remains a self-described Jew living within some atypical conception of the Jewish milieu. As Taylor argues (2007), notions of binary membership and identity largely miss the significance of marginality. My data shows that boundaries are more malleable than they are typically assumed to be in terms of the indistinct affiliations professed through interviews - given that participants express how the jargon of typical organisational categories preclude their lived experiences. Some time-tested denominational affiliations, however, do appeal to some interlocutors, who readily articulate their positioning within standard categories of belonging such as "Modern Orthodox" or "Conservative." 
If this population remains "officially" Jewish and several participants indeed identify themselves as still belonging somewhere along the Orthodox spectrum, are they really leavetakers? They are not—strictly speaking — "exes," after all (Ebaugh, 1988). My preliminary findings show that the answer is a resounding "yes." All interlocutors still identify as "Jewish," although specific varieties of Jewish identification vary between them, with no one expressing to me that their changes in affiliation or observance rendered them ineligible from identifying as Jewish in some manner. Nevertheless, these accounts do trend towards highlighting themes of leavetaking, departure, or at least a keen sense of separation of some kind from their previous positioning within the tradition, even if their articulation of that separation and new identification remains undefined to them using existing metrics of religious belonging.

Interlocutors touched upon several common issues that led to their leavetaking, although the degree to which these issues were emphasised to me varied between them, sometimes significantly. Community hypocrisy, unmanageable standards, encapsulation, inadequate general studies education, judgmental attitudes towards outsiders, relentless community surveillance, overbearing rules, and unbelief were particularly prevalent in participants' narratives.

Leavetakers from haredism described having had largely similar experiences to leavetakers from less-traditionalist groups insofar as they related a similar trajectory of dissatisfaction, questioning, investigating alternatives, surreptitious leavetaking, outing themselves or being outed, and new identification as differently-Jewish. Mirroring Davidman's findings among former haredim in New York (2014), strictly-Orthodox participants' reasons for leaving in my project tended to correlate more closely with systematic mistreatment in the community than a personal journey towards being truer to one's self elsewhere. "Avi" related that he decided to leave haredism at a very young age: "It actually started because they were beating us constantly in school. It wasn't just, like, the school or I didn't like learning about the Torah anymore or anything like that. It had nothing to do with that. It had to do with the way we were treated." Conversely, interlocutors who described themselves as having been Orthodox but not haredi expressed more varied reasons. Ariel recalls his youth in Orthodoxy to be fairly innocuous, relating simply, "I don't attribute negativity to it. It just wasn't for me." Correspondingly, some participants related how their challenges in the community have traumatised them, while others report that observant Judaism no longer appealed to them and so they stopped living that way, moving to a different Jewish identity that they found more agreeable rather effortlessly and without significant angst or interpersonal conflict.

Profound moods of guilt and shame often accompany leavetaking even from the questioning phase, where leavetakers feel that they have betrayed their 
lineage and declined their apparent chosenness. Most participants recalled this being a significant impediment to leavetaking, and feelings of guilt and shame can linger through vestiges down the line. For example, most interlocutors recall that although they no longer observe Jewish dietary requirements, certain food taboos remain powerful — a finding in common with Davidman's work with haredim (2014) and in studies of Muslim leavetakers (Cottee, 2015). Some participants described an especially keenly-felt aversion to consuming pork products and shellfish — goods traditionally perceived as being especially verboten - for reasons they cannot easily articulate. When I asked participant "Dov" why he still avoids these foods, he replied, "I want to stay a little bit part of my parents' community deep down, and that's just-it's a little way to do that? To represent, like, I'm still 'traditional'. For some reason I want to stayeven if it's a little bit-like, anchored to the tradition. It may not be a logical thing, but it's just, certain things just stay with you."

Losing faith in God and the authority of the Torah was cited as significant in a minority of leavetaker narratives, with the majority of respondents relating instead that criticism towards and from the Jewish community were intrinsic to their leavetaking. Orthodoxy and orthopraxy remain significant issues throughout, since participants recognise these aspects of religious life as encompassing normative Jewish observance while privileging one (usually orthopraxy) over the other-at least publically—raising crucial questions about sincerity, performativity, and embodiment.

All interlocutors described having happier, more gratifying and more meaningful relationships with Judaism upon leavetaking from their previous Orthodoxy. Although criticisms of the tradition and community were sometimes fierce, many participants insisted that their experiences are not necessarily typical. Indeed, several expressed how there can be tremendous joy, beauty, and fulfilment in observant Judaism even if they did not find it personally workable. This finding highlights that results may vary in Orthodox leavetaking, and that one need not necessarily feel acrimony towards the tradition to disaffiliate from it.

Divergences along gendered lines are evident in my data, with women finding it more challenging to live up to community expectations of ascribed piety than men did. Participant "Adina" discussed self-presentation inside and out of the community's purview: "I went out with friends shopping, and it was on Shabbat. And I was nervous that I'd see anyone. I went out, I bought a blonde wig, to wear. Like, I'm gonna run into twenty people I know. So, yeah. I dressed up. That probably sounds crazy. I was like sixteen or seventeen. I put it back on until I got safely [back] inside the house." Dress was less central in men's accounts, given that gender roles in the community tend to 
underscore female trappings and sexuality as being especially indicative of observance and general status, yet wearing (or not wearing) the kippah (skullcap) was indeed described as being a powerful exterior mark of membership for many men.

Several interlocutors expressed finding themselves at the margins of or near to the tradition and existing in a blind spot that remains popularly unclassified-an especially salient finding. Most participants described Judaism as being a cafeteria tradition-without this term's pejorative connotations-within which they feel authentic Judaism is most accessible through choosing what elements are meaningful to them and disregarding to various degrees those that are not, emphasising individualisation. As such, nearly everyone dismissed a rigidly-defined category of "Orthodox" observance in favour of a far broader variety of observances that they can accept or reject as appropriate. This picking-and-choosing is typically perceived as being unworkable in the wider Orthodox ethos, where religious identifications and resulting comportment must fit into largely inflexible categories wherein an individual is either "observant" or not, determined by their willingness to submit to normative religious obligations.

Furthermore, religious leavetaking is not necessarily monodirectional, as some participants related returning to observance later in life. For example, Ariel articulated how he left observant Judaism but eventually returned, albeit to an observance level different to the kind he rejected in his youth. "I think that the official phrase is 'took a break," Ariel shares, acknowledging that although he usually keeps kosher nowadays, he will occasionally eat in a nonkosher establishment when he is confident that no Orthodox Jews who might see and recognise him are in the immediate vicinity. Ariel does not find his ability to operate effectively in both worlds to be phony or especially burdensome.

Leavetaking from observant Judaism is not necessarily deconversion or becoming an "ex"; this process can entail reaffirming certain aspects of Jewish experiences alongside reshaping or suspending elements that a person finds problematic. Regardless of their technically-indissoluble station as Jews, leavetakers could very well say that they are finished with Jewish rituals and belief, living outside of Judaism perhaps save for some deeply-encoded vestiges and the tradition's ethnic dimension. But not everyone chooses this path, as per this study's findings. 
Some people resist qualifying theirJudaism as they once did, arguing that rigid denominational classifications constrain their oftentimes ongoing journey to find an appealing, meaningful, socially-conscious, and sensible religious, social, and ethnic identity within Judaism. Binary categories privileging identification with either "insiders" or "outsiders" in the tradition miss this crucial element, and are therefore no longer sufficient on their own in a robust examination of religious change. According to my data, Jewish "leavetakers" can and sometimes do remain inside that same tradition while still taking leave from certain aspects of it, and marginal leavetaker narratives endure as pertinent fixtures of contemporary Jewish experience in Canada.

\section{References}

Attia, P.R. 2008. "Runaway Youth from Ultra-Orthodox Jewish Homes: A Qualitative Study." PhD. New York University, United States.

Auslander, S. 2007. Foreskin's Lament: A Memoir. New York: Riverhead.

Bar-Lev, M., Leslau, A., and Ne'eman, N. 1997. "Culture Specific Factors Which Cause Jews in Israel to Abandon Religious Life.” In M. Bar-Lev and W. Shaffir, eds, Leaving Religion and Religious Life. Greenwich: JAI Press, 185-204.

Beckford, J.1985. Cult Controversies: The Societal Responses to New Religious Movements. New York: Tavistock.

Berger, R. 2014. "Going OTD: The Experience of Leaving Ultra-Orthodox Jewish Communities." Jewish Journal of Sociology . 56:1, 2, 75-98.

Cottee, S. 2015. The Apostates: When Muslims Leave Islam. New York: Oxford University Press.

Davidman, L. 2014. Becoming Un-Orthodox: Stories of Ex-HasidicJews. New York: Oxford University Press.

Davidman, L., and Greil, A.L. 2007. "Characters in Search of a Script: The Exit Narratives of Formerly Ultra-Orthodox Jews." Journal for the Scientific Study of Religion. 46:2, 201-216.

Deen, S. 2015. All Who Go Do Not Return. Minneapolis: Graywolf Press.

Deitsch, C. 2015. Here and There: Leaving Hasidism, Keeping My Family. Toronto: Random House.

Ebaugh, H.R. 1988. Becoming an EX: The Process of Role Exit. Chicago: University of Chicago Press.

Eichenstein, I. 2013. The Rebel and The Rabbi's Son. Birmingham: Oakstone.

Fader, A. 2017. "Ultra-Orthodox Jewish Interiority, the Internet, and the Crisis of Faith." HAU: Journal of Ethnographic Theory. 7:1, 185-206. 
Feldman, D. 2012. Unorthodox: The Scandalous Rejection of My Hasidic Roots. New York: Simon and Schuster.

Feldman, D. 2014. Exodus: A Memoir. New York: Penguin.

Frankenthaler, L. 2004. "Leaving Ultra-Orthodox Judaism: Defection as Deconversion." MA. Hebrew University, Israel.

Frankenthaler, L. 2015. "Dialogical Deconversion: Understanding Undercover Infidelity." Journal of Religion and Society. 17:1, 1-17.

Hartman, H., and Hartman, M. 1999. "Jewish Identity, Denomination and Denominational Mobility." Social Identities. 5:3, 279-311.

Herzbrun, M.B. 1999. "Loss of Faith: A Qualitative Analysis of Jewish Nonbelievers." Counseling and Values. 43:2, 129-141.

Lax, L. 2015. Uncovered: How I Left Hasidic Life and Finally Came Home. Berkeley: She Writes Press.

Lazerwitz, B. 1995. "Denominational Retention and Switching Among American Jews." Journal for the Scientific Study of Religion. 34:4, 499-506.

Lazerwitz, B., and Harrison, M. 1980. "A Comparison of Denominational Identification and Membership." Journal for the Scientific Study of Religion. 19:4, 361-367.

Mann, R. 2007. The Rabbi's Daughter: A Memoir. New York: Random House.

Pew Research Centre. 2013. "A Portrait of Jewish Americans: Findings from a Pew Research Center Survey of U.S. Jews, 2013." Pew Research Centre, Washington.

Phillips, B.A. 2010. "Accounting for Jewish Secularism: Is a New Cultural Identity Emerging?" Contemporary Jewry. 30:1, 63-85.

Phillips, B.T., and Kelner, S. 2006. "Reconceptualizing Religious Change: EthnoApostasy and Change in Religion among American Jews." The National Jewish Population Survey 2000-1. Sociology of Religion. 67:4, 507-524.

Roof, W.C., and Hoge, D.R. 1980. "Church Involvement in America: Social Factors Affecting Membership and Participation." Review of Religious Research. 21:4, 405S-426S.

Sands, R.G., Marcus, S.C., and Danzig, R.A. 2006. "The Direction of Denominational Switching in Judaism." Journal for the Scientific Study of Religion. 45:3, 437-447.

Sarna, J.D. 2004. American Judaism: A History. New Haven: Yale University Press.

Shaffir, W. 1991. "Conversion Experiences: Newcomers to and Defectors from Orthodox Judaism." In Z. Sobel and B. Beit-Hallahmi, eds, Tradition, Innovation, Conflict:Jewishness and Judaism in Contemporary Israel. Albany: State University of New York Press, 173-202.

Shaffir, W., and Rockaway, R. 1987. "Leaving the Ultra-Orthodox Fold: The Defection of Haredi Jews." Jewish Journal of Sociology. 29:2, 97-114.

Stadler, N. 2009. Yeshiva Fundamentalism: Piety, Gender, and Resistance in the ultraOrthodox World. New York: New York University Press.

Stromberg, P. 1993. Language and Self-Transformation: A Study of the Christian Conversion Narrative. Cambridge: Cambridge University Press. 
Taylor, C. 2007. A Secular Age. Cambridge: Harvard University Press.

Topel, M.F. 2012. Jewish Orthodoxy and its Discontents: Religious Dissidence in Contemporary Israel. Lanham: University Press of America.

Trencher, M. 2016. "Starting a Conversation: A Pioneering Survey of those who have Left the Orthodox Community." At http://nishmaresearch.com/social-research. html. Accessed 30/7/2019.

Troen, I. 2016. “Secular Judaism in Israel." Society. 53:2, 153-162.

Vincent, L. 2014. Cut Me Loose: Sin and Salvation after my Ultra-Orthodox Girlhood. New York: Penguin.

Weiskopf, R. 2016. "Exploring the Subjective Experience of Ultra-Orthodox Defectors." PsyD. William James College, United States.

Winston, H. 2005. Unchosen: The Hidden Lives of Hasidic Rebels. Boston: Beacon Press. 